Purdue University Purdue e-Pubs

$5-28-2008$

\title{
Microchannel Size Effects on Local Flow Boiling Heat Transfer to a Dielectric Fluid
}

Tannaz Harirchian

Purdue University, tharirch@ecn.purdue.edu

S V. Garimella

Purdue University, sureshg@purdue.edu

Follow this and additional works at: http:/ / docs.lib.purdue.edu/coolingpubs

Harirchian, Tannaz and Garimella, S V., "Microchannel Size Effects on Local Flow Boiling Heat Transfer to a Dielectric Fluid" (2008). CTRC Research Publications. Paper 92.

http://dx.doi.org/10.1016/j.ijheatmasstransfer.2008.03.013

This document has been made available through Purdue e-Pubs, a service of the Purdue University Libraries. Please contact epubs@purdue.edu for additional information. 


\title{
Microchannel Size Effects on Local Flow Boiling Heat Transfer to a Dielectric Fluid ${ }^{1}$
}

\author{
Tannaz Harirchian and Suresh V. Garimella ${ }^{2}$ \\ School of Mechanical Engineering and Birck Nanotechnology Center \\ 585 Purdue Mall, Purdue University \\ West Lafayette, IN 47907-2088 USA
}

\begin{abstract}
Heat transfer with liquid-vapor phase change in microchannels can support very high heat fluxes for use in applications such as the thermal management of high-performance electronics. However, the effects of channel cross-sectional dimensions on the two-phase heat transfer coefficient and pressure drop have not been investigated extensively. In the present work, experiments are conducted to investigate the local flow boiling heat transfer of a dielectric fluid, Fluorinert FC-77, in microchannel heat sinks. Experiments are performed for mass fluxes ranging from 250 to $1600 \mathrm{~kg} / \mathrm{m}^{2} \mathrm{~s}$. Seven different test pieces made from silicon and consisting of parallel microchannels with nominal widths ranging from 100 to $5850 \mu \mathrm{m}$, all with a nominal depth of $400 \mu \mathrm{m}$, are considered. An array of temperature sensors on the substrate allows for resolution of local temperatures and heat transfer coefficients. The results of this study show that for microchannels of width $400 \mu \mathrm{m}$ and greater, the heat transfer coefficients corresponding to a fixed wall heat flux as well as the boiling curves are independent of channel size. Also, heat transfer coefficients and boiling curves are independent of mass flux in the nucleate boiling region for a fixed channel size, but are affected by mass flux as convective boiling dominates. A strong dependence of pressure drop on both channel size and mass flux is observed. The experimental results are compared to predictions from a number of existing correlations for both pool boiling and flow boiling heat transfer.
\end{abstract}

Keywords: Microchannel, boiling, two-phase heat transfer, dielectric liquid, size effect.

\footnotetext{
${ }^{1}$ Submitted for possible publication in International Journal of Heat and Mass Transfer, October 2007, and in revised form, February 2008

${ }^{2}$ Author to whom correspondence should be addressed: 765-494-5621, sureshg@purdue.edu
} 


\section{NOMENCLATURE}

$A_{b} \quad$ heat sink base area, $\mathrm{m}^{2}$

$A_{f} \quad$ wetted area of a fin, $\mathrm{m}^{2}$

$A_{w} \quad$ total wetted area of microchannels, $\mathrm{m}^{2}$

Bo boiling number, $q^{\prime \prime} /\left(G h_{f g}\right)$

$C_{1}, C_{2}$ constants in heat loss-temperature relation

Co convective number, $(1 / x-1)^{0.8}\left(\rho_{g} / \rho_{f}\right)^{0.5}$

$c_{p} \quad$ specific heat, $\mathrm{J} \mathrm{kg}^{-1} \mathrm{~K}^{-1}$

d microchannel depth, $\mathrm{m}$

D diameter, $\mathrm{m}$

$D_{h} \quad$ hydraulic diameter, $\mathrm{m}$

$f \quad$ friction factor

F enhancement factor, equations (12), (19), (25), (35)

Fr Froude number, $G^{2} /\left(\rho^{2} g D\right)$

$F_{f l} \quad$ fluid parameter, equation (30)

$F_{P F} \quad$ pressure correction factor, equation (9)

G mass flux, $\mathrm{kg} \mathrm{m}^{-2} \mathrm{~s}^{-1}$

$h$ heat transfer coefficient, $\mathrm{W} \mathrm{m}^{-2} \mathrm{~K}^{-1}$

$h_{f g} \quad$ latent heat of vaporization for FC-77, $\mathrm{J} \mathrm{kg}^{-1}$

$k$ thermal conductivity, $\mathrm{W} \mathrm{m}^{-1} \mathrm{~K}^{-1}$

L microchannel length, heat sink width, $\mathrm{m}$

$\dot{m} \quad$ mass flow rate, $\mathrm{kg} \mathrm{s}^{-1}$

$M \quad$ molecular weight, $\mathrm{kg} \mathrm{kmol}^{-1}$

MAPE mean absolute percentage error $n$ exponent in the Gorenflo correlation, equation (9)

$N \quad$ number of microchannels in a heat sink

$\mathrm{Nu} \quad$ Nusselt number

$p$ pressure, $\mathrm{Pa}$

$p_{r} \quad$ reduced pressure, $p / p_{c r}$

$P \quad$ pumping power, $\mathrm{W}$

Pr Prandtl number

$\dot{q}_{\text {net }} \quad$ heat dissipated to the fluid, W

$\dot{q}_{\text {loss }} \quad$ heat loss, $\mathrm{W}$

$\dot{q} \quad$ heat dissipated from the heat sources, W

$q_{b}^{\prime \prime} \quad$ base heat flux, $\mathrm{W} \mathrm{m}^{-2}$

$q_{w}^{\prime \prime} \quad$ wall heat flux, $\mathrm{W} \mathrm{m}^{-2}$

$R \quad$ resistance obtained by calibration, $\Omega$

Re Reynolds number

$R_{p} \quad$ surface roughness parameter, $\mu \mathrm{m}$

S suppression factor

$t \quad$ heat sink thickness, $m$

$T \quad$ temperature, ${ }^{\circ} \mathrm{C}$

$T_{\text {ref }} \quad$ reference temperature: $T_{f}$ in singlephase region and $T_{\text {sat }}$ in two-phase region, ${ }^{\circ} \mathrm{C}$

$V \quad$ voltage applied to the heat sources, $\mathrm{V}$

w microchannel width, $\mathrm{m}$

$w_{f} \quad$ fin width, $m$

We Weber number, $\left(G^{2} D\right) /(\rho \sigma)$

$X \quad$ vapor quality

$X \quad$ Martinelli parameter 


\section{Greek symbols}

$\Delta p \quad$ pressure drop, $\mathrm{Pa}$

$\Delta p_{\text {sat }} \quad p_{\text {sat }}\left(T_{w}\right)-p_{f}, \mathrm{~Pa}$

$\Delta T_{\text {sat }} \quad T_{w}-T_{\text {sat }}, \mathrm{K}$

$\phi_{f} \quad$ two-phase multiplier

$\rho \quad$ density, $\mathrm{kg} \mathrm{m}^{-3}$

$\eta_{f} \quad$ efficiency of a fin in the microchannel heat sink

$\eta_{o} \quad$ overall surface efficiency of the microchannel heat sink

$\mu \quad$ dynamic viscosity, $\mathrm{kg} \mathrm{m}^{-1} \mathrm{~s}^{-1}$

$\sigma \quad$ surface tension, $\mathrm{N} \mathrm{m}^{-1}$

$\psi \quad h_{t p} / h_{s p}$

\section{Subscripts}

$0 \quad$ reference value

$c b \quad$ convective boiling

$\mathrm{Cr} \quad$ critical $d \quad$ diode temperature sensor

e exit

exp experimental

$f \quad$ liquid

fd fully developed

g vapor

in channel inlet

$n b \quad$ nucleate boiling

pred predicted

sat saturated liquid

si $\quad$ silicon

sp $\quad$ single phase

$t \quad$ turbulent

tp two phase

tt turbulent liquid-turbulent vapor

$v \quad$ laminar

w bottom wall of the channels

\section{INTRODUCTION}

Boiling in microchannel heat sinks offers extremely high heat transfer rates, while at the same time, maintaining relatively uniform wall temperatures. Although progress has been made in characterizing heat transfer and pressure drop during flow boiling in microchannels, a fundamental understanding of boiling mechanisms and comprehensive flow regime maps for such flows are unavailable [1].

A number of studies in recent years have attempted to better understand the flow patterns of boiling in microchannels using different working fluids [2,3]. Peng and Wang [4] experimentally investigated single-phase convection and flow boiling of water in microchannels of cross section $600 \times 700 \mu \mathrm{m}$. They showed that unlike conventional-sized tubes, partial nucleate boiling was not observed in the subcooled region and fully developed boiling was induced much earlier than at the macroscale. Kew and Cornwell [5] experimentally studied two-phase flow and heat transfer with refrigerant R141b in circular tubes of diameter 1.39 to $3.69 \mathrm{~mm}$. They proposed a threshold hydraulic diameter below which conventional correlations were not suitable for the prediction of flow boiling heat transfer. Qu and Mudawar [6] studied convective boiling heat transfer, two-phase flow patterns, and pressure drop in parallel 
microchannels of $231 \mu \mathrm{m}$ width and $712 \mu \mathrm{m}$ depth using water as the working fluid. They argued that unlike in the case of fluorochemicals, it is difficult to sustain bubbly flow regimes in boiling of water in microchannels because of the high surface tension and large contact angle of water; a slug flow regime was found to develop shortly after the incipience of boiling. Also, the flow patterns were strongly influenced by the applied heat flux. Jiang et al. [7] carried out experiments with water in triangular silicon microchannels of hydraulic diameter 26 and $53 \mu \mathrm{m}$ and observed that annular flow developed at a relatively low heat flux, such that evaporation at the liquid film/vapor core interface was the dominant heat transfer mode over a wide range of input powers. Hence, no boiling plateau was observed in the boiling curve and the wall temperature increased as the heat flux was increased.

Use of dielectric liquids in microchannel heat sinks has drawn recent attention since the working fluid in the microchannel heat sinks can be in direct contact with the electronics. Despite their poorer thermal properties as compared to water, perfluorocarbons are particularly suitable for direct contact cooling due to their high electrical resistivity. Fluorinert FC-77, a typical perfluorocarbon liquid, is characterized by a specific heat and a latent heat of vaporization of $1100 \mathrm{~J} / \mathrm{kg} \mathrm{K}$ and $89 \times 10^{3} \mathrm{~J} / \mathrm{kg}$, respectively, with electrical resistivity on the order of $10^{15} \mathrm{ohm}-\mathrm{cm}$. Although there have been a number of studies on pool boiling of perfluorocarbon liquids and the effect of surface enhancement [8], investigations of flow boiling in microchannels using perfluorocarbon liquids have been limited. Chen and Garimella [9] conducted experiments to study the physics of boiling in parallel silicon microchannels with a cross section of 389 $\mu \mathrm{m} \times 389 \mu \mathrm{m}$ using FC-77 as the working fluid. They tested three different flow rates and observed bubbly and slug flow patterns at lower heat fluxes and wispy-annular and churn-flow regimes at higher heat fluxes. Zhang et al. [10] performed an experimental study of flow boiling of FC-72 for three different orientations of a microchannel heat sink: vertical up-flow, vertical down-flow, and horizontal flow. The heat sink consisted of parallel microchannels $200 \mu \mathrm{m}$ wide and $2 \mathrm{~mm}$ deep. They observed boiling to occur in isolated bubble flow and slug flow regimes. Annular flow was not observed due to the short length of the channels. Warrier et al. [11] performed single-phase and boiling experiments in horizontal parallel aluminum microchannels of hydraulic diameter $750 \mu \mathrm{m}$ with FC-84 as the test fluid. They tested different mass flow rates and inlet subcooling conditions and proposed correlations for both pressure drop and heat transfer.

The effect of flow rate on microchannel flow boiling has been considered in a number of studies. However, few have arrived at clear conclusions on the effect of mass flux on boiling heat transfer and pressure drop. Chen and Garimella [9] compared the boiling heat transfer coefficients and pressure drops for flow rates of 260,349 , and $445 \mathrm{~kg} / \mathrm{m}^{2} \mathrm{~s}$. Liu and Garimella [12] carried out an experimental study of flow boiling heat transfer in microchannels $(275 \mu \mathrm{m} \times 636 \mu \mathrm{m})$ cut into a copper block, using DI water with mass fluxes ranging from 341 to $936 \mathrm{~kg} / \mathrm{m}^{2} \mathrm{~s}$. Chen and Garimella [13] performed an experimental 
study of flow boiling of FC-77 in a copper microchannel (10 channels, $405 \mu \mathrm{m} \times 2.5 \mathrm{~mm}$ ) heat sink at flow rates ranging from 80 to $133 \mathrm{~kg} / \mathrm{m}^{2} \mathrm{~s}$. Pate et al. [14] explored two-phase heat transfer in parallel microchannels with hydraulic diameter of $253 \mu \mathrm{m}$ using FC-72 as the test fluid. Six re-entrant type cavities, spaced evenly on the base of each channel, were used to promote controlled nucleation. Mass fluxes in the range of $535-2138 \mathrm{~kg} / \mathrm{m}^{2}$ s were considered. All these studies $[9,12,13,14]$ showed that beyond the onset of nucleate boiling, the boiling curves collapsed on a single curve for all mass flow rates; as the heat flux was increased further, the curves diverged and became dependent on mass flux. Lin et al. [15] performed an experimental study of two-phase flow of refrigerant R141b in circular tubes of diameter of 1.8, 2.8, 3.6 mm and one square tube of $2 \times 2 \mathrm{~mm}^{2}$ with different mass fluxes ranging from 50 to $3500 \mathrm{~kg} / \mathrm{m}^{2} \mathrm{~s}$. Both nucleate and convective boiling mechanisms were said to occur in the tubes and the local heat transfer coefficient was found to be a weak function of mass flux while the mean heat transfer coefficient was independent of mass flux.

Although a large number of studies of microchannel flow boiling have been reported, few have systematically explored the effect of microchannel dimensions on the thermal transport. While a few studies have considered the effect of microchannel size on flow boiling patterns and the transition between different flow regimes, the effect of microchannel size on heat transfer coefficient and pressure drop has been largely unexplored. Lin et al. [15] showed that the transition from nucleate to convective boiling at high heat flux occurred at higher qualities in the smaller diameter tubes. In the absence of dryout in the saturation boiling region, they found that the mean heat transfer coefficient varied only slightly with the tube diameter and was mainly a function of heat flux. Zhang et al. [16] conducted experiments in single silicon microchannels of 27-171 $\mu \mathrm{m}$ hydraulic diameters and different surface roughnesses with DI water to study bubble nucleation, flow patterns, and transient pressure fluctuations. They showed that in $171 \mu \mathrm{m}$-diameter channels, a typical nucleation process occurs and the bubbles formed contribute to an annular flow pattern. In channels smaller than $50 \mu \mathrm{m}$ in hydraulic diameter, the bubble nucleation mechanism was found to be that of eruption boiling and mist flow developed almost right after single-phase flow ended because of the large amount of wall superheat. Hence, no temperature plateau was observed. The boiling mechanism was found to be determined by the wall surface conditions rather than the channel dimensions. Bergles et al. [17] also performed an analysis and showed that incipience of boiling in a subcooled flow was most likely governed by the nucleation sites in the walls and not by the channel size. Saitoh et al. [18] experimentally investigated the boiling heat transfer of refrigerant R-134a flow in three horizontal tubes of diameter $0.51,1.12$, and $3.1 \mathrm{~mm}$ and mass fluxes ranging from 150 to $450 \mathrm{~kg} / \mathrm{m}^{2} \mathrm{~s}$. Their study showed that the local heat transfer coefficient increased with increasing mass flux in larger tubes but was not significantly affected by mass flux in smaller tubes. The heat transfer coefficient increased with increasing heat flux in all three tubes. The contribution of 
forced convective evaporation to the boiling heat transfer decreased with decreasing tube diameter. Lee et al. [19] investigated the effect of microchannel height on nucleation-site activity and bubble dynamics using three fluids: water, methanol and ethanol. The heat sink consisted of ten parallel microchannels fabricated in a silicon wafer, with width ranging from 150 to $9000 \mu \mathrm{m}$ and height ranging from 5 to 510 $\mu \mathrm{m}$. They found that the bubble nucleation activity was dependent on channel height for all fluids tested. Lee et al. [20] explored the effect of channel shape on two-phase flow patterns in DI water. The microchannel heat sink they tested consisted of ten shallow, nearly rectangular silicon microchannels of $120 \mu \mathrm{m}$ width and $14 \mu \mathrm{m}$ depth. They studied bubble dynamics and two-phase flow patterns and compared the results to similar work by Jiang et al. [7] in triangular microchannels with hydraulic diameter of $26 \mu \mathrm{m}$. Dupont and Thome [21] studied the effect of diameter on flow boiling heat transfer and transition from macro- to microchannel evaporation using a three-zone flow boiling model based on evaporation of elongated bubbles in microchannels. The model predicted an increase in heat transfer coefficient with a decrease in diameter for low values of vapor quality and a decrease in heat transfer coefficient for large vapor qualities.

In view of the absence of any systematic studies in the literature on the effect of microchannel dimensions on heat transfer coefficient and pressure drop, the objective of the present work is to investigate the effect of mass flow rate and channel size on boiling heat transfer in microchannel heat sinks with a dielectric fluid, FC-77. Boiling curves, heat transfer coefficients, and pressure drops are presented and compared for a range of flow rates and microchannel sizes, and design criteria for microchannel heat sinks are discussed. Also, the heat transfer coefficients obtained in this work are compared to values predicted using a number of existing correlations for pool boiling and saturated flow boiling in large and small channels.

\section{EXPERIMENTAL SETUP AND PROCEDURES}

\section{Flow loop}

A schematic diagram of the experimental test loop is shown in Figure 1. A magnetically coupled gear pump drives the dielectric liquid, FC-77, through the closed loop. A preheater installed upstream of the test section heats the coolant to the desired subcooling temperature at the entrance of the microchannels, and a liquid-to-air heat exchanger located downstream of the test section cools the fluid before it enters the reservoir. The liquid is fully degassed before initiating each test using the two degassing ports and the expandable reservoir. Details of the expandable reservoir design and the degassing procedure are available in Chen and Garimella [22]. A flow meter with a measurement range of 20-200 $\mathrm{ml} / \mathrm{min}$ monitors the flow rate through the loop and five T-type thermocouples measure the fluid temperature before and after the preheater, before and after the test section, and after the heat exchanger. The pressure 
in the outlet manifold of the test section is maintained at 1 atmosphere. The pressure at the inlet manifold and the pressure drop across the microchannel array are measured using a pressure transducer (Gems Sensors, 2200 series) and a differential pressure transducer (Omega, PX2300 series), respectively.

\section{Test Section}

The test section shown in Figure 2(a) consists of a $12.7 \mathrm{~mm} \times 12.7 \mathrm{~mm}$ silicon microchannel heat sink with thickness of $650 \mu \mathrm{m}$, mounted on a printed circuit board (PCB). The PCB is installed on a quick-connect board with an insulating G10 piece in between. A polycarbonate top cover above the test piece provides an enclosed passage for the liquid and is sealed with an o-ring. To avoid melting of the polycarbonate at high die temperatures, a $12.7 \mathrm{~mm} \times 12.7 \mathrm{~mm}$ Pyrex sheet of thickness $0.4 \mathrm{~mm}$ with a high melting point is sandwiched between the silicon die and the top cover and forms the top wall of the microchannels.

As detailed in Figure 2(b), parallel microchannels are cut on the top surface of the silicon chip using a dicing saw. The width, depth, and number of microchannels in each heat sink are listed in Table 1. The surface roughnesses for the side and bottom walls are measured using a probe-type profilometer and an optical profilometer, respectively. The bottom wall of the $100 \mu \mathrm{m}$ wide microchannels has an average roughness of $0.1 \mu \mathrm{m}$. Wider microchannels were made with a number of cuts; this process imparts a waviness to the bottom surfaces resulting in an average roughness of 0.8 to $1.4 \mu \mathrm{m}$ for the different test pieces; the average roughness in the region of a single cut is $0.2 \mu \mathrm{m}$. The average surface roughness of the side walls is $0.1 \mu \mathrm{m}$ for all test pieces.

A $5 \times 5$ array of resistance heat sources and a like array of temperature sensing diodes are fabricated on the other side of the chip, providing uniform heat flux to the back side of the microchannels and local measurements of the base temperature. The resistance of each heating element is measured at temperatures up to $130^{\circ} \mathrm{C}$. Since the resistances of all the heat sources are almost identical, they are connected in parallel and are supplied with a single DC voltage in order to provide a uniform heat flux to the back of the microchannels. The amount of heat generated by each source is obtained from the calibrated resistance of the corresponding element and the applied voltage.

For a given current passing through a diode temperature sensor, the voltage drop across the diode depends on the temperature. To obtain the voltage-temperature relationship for each diode, the test piece is calibrated in a convection oven. Twenty five individual current sources are used to apply $100 \mu \mathrm{A}$ to each diode and the voltage drop across each diode is measured at seven temperatures ranging from $25^{\circ} \mathrm{C}$ to $115^{\circ} \mathrm{C}$.

The calculated local heat transfer coefficients presented in this paper are based on measurements from the temperature sensor at location 3 in Figure 2(b), which is along the centerline of the test piece near the exit. 
More details of the individual heaters, diode temperature sensors, calibration procedures, test section assembly, and test loop are available in Chen and Garimella [9] and Lee and Garimella [23].

\section{Experimental Procedures}

Experiments are conducted for seven test pieces with a constant channel depth of $400 \mu \mathrm{m}$ and different channel widths ranging from $100 \mu \mathrm{m}$ to $5850 \mu \mathrm{m}$ to study the effect of microchannel width over a wide range of micro- to macro-scale dimensions on the boiling heat transfer coefficients and pressure drops as a function of mass flux. Four mass flux values ranging from 250 to $1600 \mathrm{~kg} / \mathrm{m}^{2} \mathrm{~s}$ are investigated for each test piece to map the effect of flow velocity on boiling. The dimensions of the test pieces and the flow rates are summarized in Table 1. While the actual values are used for all the calculations in this study, "nominal" values are used for easier reference of the dimensions and the flow rates in the text. As listed in this table, there are five test pieces with width ranging from $100 \mu \mathrm{m}$ to $1000 \mu \mathrm{m}$ and two test pieces with much larger channel widths of $2200 \mu \mathrm{m}$ and $5850 \mu \mathrm{m}$.

Before initiating each test, the liquid in the test loop is fully degassed to help reduce flow instabilities [22]. It is then driven into the loop at a constant flow rate and preheated to approximately $92^{\circ} \mathrm{C}$, providing $5^{\circ} \mathrm{C}$ of subcooling at the inlet of the channels. For each test, the flow rate is kept constant throughout the test and the heat flux to the chip is increased from zero to the point at which the maximum wall temperature reaches $150^{\circ} \mathrm{C}$, which is a safe operating temperature for the integrated heaters and temperature sensors. Heat flux values approaching critical heat flux are avoided since the corresponding temperatures could cause the solder bumps in the test chip to melt. A throttling valve positioned upstream of the test section serves to suppress instabilities in the microchannel heat sink. Nevertheless, mild flow reversals at the inlet of the microchannels were observed at the highest heat fluxes studied, for microchannels of width $400 \mu \mathrm{m}$ and smaller, and for low mass fluxes. However, these instabilities did not affect the inlet fluid temperature which is held constant throughout each test.

\section{DATA REDUCTION}

The heat transfer rate to the fluid, $\dot{q}_{n e t}$, in the microchannels is obtained from an energy balance for each heating element:

$$
\dot{q}_{\text {net }}=\dot{q}-\dot{q}_{\text {loss }}
$$

in which $\dot{q}$ is the total heat dissipated from each of the twenty five heat sources and is calculated as $\dot{q}=V^{2} / R$. The heat loss, $\dot{q}_{\text {loss }}$, consists of losses through natural convection from the test setup surfaces to the surrounding air, radiation from these surfaces, and conduction through the PCB and the top cover, and is determined as follows. Before the test section is charged with liquid, a constant voltage is applied to the heaters. When the readings of the diode temperature sensors reach a steady state, the 
temperature of each sensor is recorded and correlated to the heat dissipated from the corresponding heater at that location. This procedure is repeated for several levels of input power and a linear relation in the form of $\dot{q}_{\text {loss }}=c_{1} T_{d}+c_{2}$ is obtained, where $c_{1}$ and $c_{2}$ are constants and are slightly different at each location and for different test pieces. The linearity of the heat loss-temperature relationship indicates that the losses are primarily due to conduction of heat from the test section to the ambient.

The local heat transfer coefficient corresponding to each heated element area is then calculated from

$$
h=\frac{q_{w}^{\prime \prime}}{\eta_{o}\left(T_{w}-T_{s a t}\right)}
$$

where $T_{w}$ is the local microchannel wall temperature as shown in Figure 3. This temperature is corrected for the microchannel base thickness using

$$
T_{w}=T_{d}-\frac{q_{b}^{\prime \prime}(t-d)}{k_{s i}}
$$

where $T_{d}$ is the temperature measured by an integrated diode. $\eta_{o}$ is the overall surface efficiency of the microchannel heat sink and is defined as

$$
\eta_{o}=1-\frac{N A_{f}}{A_{w}}\left(1-\eta_{f}\right)
$$

where $A_{f}=2 L d$ is the wetted area of a fin, $A_{w}=N(w+2 d) L$ is the total wetted area of the microchannels, and $\eta_{f}=\frac{\tanh m d}{m d}$ is the efficiency of a fin with an adiabatic tip, with $m^{2}=2 h / k_{s i} w_{f}[24]$. In these calculations, the wall between each microchannel is considered as a fin and the tips of the fins are assumed to be adiabatic since the heat transfer from the fin tips to the top cover is much lower than the heat transfer from the fin walls to the liquid inside the channels. As a first approximation, $\mathrm{h}$ is calculated assuming an overall surface efficiency of $100 \%$; this value of $\mathrm{h}$ is used to calculate the fin efficiency and overall efficiency, which then lead to an updated value for $h$. This iteration is continued till a converged value is obtained. The overall efficiencies of the heat sinks tested ranged from 96.5 to $99.9 \%$.

The local wall heat flux used in Eq. (2) is the net heat flux added to the fluid as shown in Figure 3 and is calculated using the total wetted area as

$$
q_{w}^{\prime \prime}=\dot{q}_{n e t} /\left(A_{w} / 25\right)
$$


The heat flux used in finding the heat loss through the base of the microchannel heat sink and hence, calculating the wall temperature in Eq.(3), is the base heat flux and is calculated using the chip base area, $A_{b}=L \times L$, which is the same as the combined area of all the heat sources

$$
q_{b}^{\prime \prime}=\dot{q}_{\text {net }} /\left(A_{b} / 25\right)
$$

In Eqs. (5) and (6), the areas are divided by 25 because $\dot{q}_{\text {net }}$ is defined as the net heat dissipated from one of the twenty five heat sources.

The exit vapor quality is calculated from an energy balance as follows

$$
x_{e}=\frac{1}{h_{f g}}\left(\frac{\dot{q}_{n e t}}{\dot{m}_{f}}-c_{p, f}\left(T_{\text {sat }}-T_{\text {in }}\right)\right)
$$

\section{Measurement Uncertainties}

The measurement uncertainties for the flow meter and the pressure transducers are $1 \%$ and $0.25 \%$ of full scale, respectively. The uncertainties in the measurements of the channel dimensions, the T-type thermocouples, and the diode temperature sensors are $\pm 15 \mu \mathrm{m}, \pm 0.3^{\circ} \mathrm{C}$ and $\pm 0.02^{\circ} \mathrm{C}$, respectively, while those for the microheater resistance and applied voltage are $0.002 \%$ and $0.004 \%$, respectively. Following a standard uncertainty analysis [25], the uncertainties associated with the wall heat flux and the heat transfer coefficient are estimated to be 1.95 to $4 \%$ and 2 to $4.2 \%$, respectively, for the cases considered. These uncertainties are primarily governed by uncertainties in the measurement of the area, since the uncertainties in the net heat transfer rate, wall temperature, and saturation temperature are relatively small.

\section{RESULTS AND DISCUSSION Boiling Curve}

Figure 4(a) and (b) show the boiling curves at four different mass fluxes for the test pieces with microchannels of width $400 \mu \mathrm{m}$ and $2200 \mu \mathrm{m}$. Both single-phase and two-phase regions are included in these plots. In the single-phase region, wall excess temperature (x-axis) is calculated with respect to the mean fluid temperature at the corresponding heat flux, while in the two-phase region, the saturation temperature of the liquid is employed. The saturation temperature takes different values at different points on the plots depending on the local pressure. As can be seen from these figures, the onset of boiling is associated with a sharp drop in the wall excess temperature. With sufficiently small heat flux increments, this temperature overshoot was observed with all the test pieces and at all mass fluxes. The maximum drop in the wall temperature, $\mathrm{T}_{\mathrm{w}}$, observed upon incipience of boiling in the $400 \mu \mathrm{m}$ wide microchannels was $8^{\circ} \mathrm{C}$ at a mass flux of $250 \mathrm{~kg} / \mathrm{m}^{2} \mathrm{~s}$. This is consistent with the results obtained by Pate et al. [14], who also observed that the wall temperature overshoot at the incipience of boiling decreased 
with increasing mass flux. Figure 4 also shows that the onset of nucleate boiling occurs at a lower temperature and a lower heat flux for a lower mass flux.

For microchannels of width $1000 \mu \mathrm{m}$ and larger, beyond the onset of nucleate boiling, curves for all mass fluxes collapse to a single curve, indicating the dominance of nucleate boiling. This is shown in Figure 4(b) for microchannels of width $2200 \mu \mathrm{m}$. At higher heat fluxes, as the convective heat transfer starts to dominate, the curves diverge and, as in the single-phase region, more heat is dissipated as mass flux increases at a fixed wall temperature. These trends are also consistent with results in the literature $[12,13,14]$. The same behavior is observed in all the smaller microchannels for mass fluxes of 700 $\mathrm{kg} / \mathrm{m}^{2} \mathrm{~s}$ and larger. However, the boiling curve for the mass flux of $250 \mathrm{~kg} / \mathrm{m}^{2} \mathrm{~s}$ deviates from those for higher mass fluxes as shown in Figure 4(a) for the $400 \mu \mathrm{m}$ microchannels. This distinct behavior of the boiling curve at the lowest mass flux in channel sizes smaller than $1000 \mu \mathrm{m}$ is due to an early transition to slug flow and annular flow regimes at lower and higher heat fluxes, respectively, in contrast to the behavior at higher mass fluxes and in larger channels.

The effect of microchannel size on the boiling curve for a fixed mass flux of $700 \mathrm{~kg} / \mathrm{m}^{2} \mathrm{~s}$ is shown in Figure 5(a). For microchannels of width $400 \mu \mathrm{m}$ and larger, the boiling curves cluster together beyond the onset of nucleate boiling. As boiling starts in these microchannels, the wall temperature has a weak dependence on the heat flux and is relatively invariant; however, at high heat fluxes the wall temperature becomes more dependent on heat flux and the boiling curves deviate for different sizes.

For the microchannels of width 100 and $250 \mu \mathrm{m}$, the wall temperature increases with increasing wall heat flux and the boiling curves are distinctly different from those of the larger microchannels. This is attributed to the rapid increase of vapor quality and early establishment of annular flow in microchannels of very small diameter $[6,7,16]$. The effect of microchannel size on the boiling curves seen in Figure 5(a) was also observed in the experiments conducted with other mass fluxes.

Further, if the base heat flux, instead of the wall heat flux, were plotted versus wall superheat temperature as is done in Figure 5(b), it is seen that for a fixed heat dissipation rate from the chip, the wall temperature increases with channel size and is much lower for the $100 \mu \mathrm{m}$ wide microchannels. In other words, more heat can be removed from the chip at a given wall temperature with the smaller microchannels. It is emphasized that the number of microchannels incorporated into the chip base area directly affects the base heat flux value; however, the heat sinks tested in this work are not optimized in terms of maximizing the number of microchannels that can be accommodated in a given footprint. Nonetheless, results for the different channel dimensions from the present work may be readily extrapolated for optimizing microchannel heat sinks by adjusting the number of microchannels present (by changing the fin width). 


\section{Heat Transfer Coefficient}

Figure 6 illustrates the effect of mass flux on the heat transfer coefficient as a function of the wall heat flux. The heat transfer coefficient increases with mass flux in the single-phase region for a fixed wall heat flux. After the onset of nucleate boiling, however, the heat transfer coefficient becomes independent of mass flux, and increases with heat flux. At high levels of wall heat flux, as the contribution from convective heat transfer begins to dominate that of nucleate boiling, the heat transfer coefficient becomes a function of mass flux and increases with increasing mass flux. Flow visualizations performed as part of this work show that the plots of heat transfer coefficient diverge from each other at the heat flux where the bubble nucleation was observed to be suppressed at the walls. Other microchannel sizes tested yielded similar trends for the dependence of heat transfer coefficient on mass flux. These results regarding the dependence of heat transfer coefficient on flow rate are also consistent with the findings of Chen and Garimella $[9,13]$.

At high heat fluxes, a decrease in heat transfer coefficient is detected. Flow visualizations revealed that this is attributed to a partial wall dryout as also reported in [9].

The influence of microchannel size on the heat transfer coefficient is illustrated in Figure 7(a). Interestingly, the heat transfer coefficient is independent of microchannel width for channels of width 400 $\mu \mathrm{m}$ and larger, and even for smaller microchannels has only a weak dependence on channel size. At the $250 \mu \mathrm{m}$ width, the heat transfer coefficients are slightly lower than for the larger sizes at any wall heat flux. For the $100 \mu \mathrm{m}$ wide microchannels, the behavior is markedly different, with the heat transfer coefficient being relatively higher at the lower heat fluxes. As the heat flux increases, the curve crosses over and is lower than for the larger microchannels. This is attributed to the high exit vapor quality for the $100 \mu \mathrm{m}$ microchannels, as illustrated in Figure 8. As a result of the high vapor qualities in the $100 \mu \mathrm{m}$ microchannels, annular flow commences at lower heat fluxes than at the larger channel sizes [16], leading to higher heat transfer coefficients at the lower heat fluxes [16, 26].

Figure 7(a) illustrates that increasing the width of the microchannels beyond $400 \mu \mathrm{m}$ (for a fixed channel depth) does not affect the heat transfer coefficient for a fixed wall heat flux, $q_{w}^{\prime \prime}$. However, from a design point of view, the dependence of heat transfer coefficient on microchannel size should be considered in terms of a given amount of heat dissipation from the chip, i.e., a fixed value of base heat flux, $q_{b}^{\prime \prime}$. Plotted in this manner, the heat transfer coefficient (as a function of base heat flux) for different microchannel sizes is presented in Figure 7(b). It is evident from this figure that for a given heat dissipation from the chip, the heat transfer coefficient increases as the microchannels width increases. However, the maximum amount of heat that can be removed from the chip increases as the microchannels become smaller due to the larger surface enhancement with the smaller microchannels. 


\section{Pressure Drop}

The pressure drop across the microchannels is plotted as a function of the average wall heat flux in Figure 9 for the $400 \mu \mathrm{m}$-wide microchannels at four different mass fluxes. The two-phase region can be clearly distinguished from the single-phase region by the sharp change in slope of the curves. In the single-phase region, the pressure drop decreases slightly with increasing heat flux due to the reduction in liquid viscosity as the liquid temperature increases. In the two-phase region, the pressure drop is strongly dependent on heat flux and increases rapidly and almost linearly with increasing heat flux due to the acceleration of vapor as well as the two-phase frictional pressure drop. These trends in pressure drop have been reported in many studies $[6,9,11,12,14]$. In both single-phase and two-phase regions, the pressure drop increases with increasing mass flux, which agrees with the results obtained by Pate et al. [14]. Chen and Garimella [9], however, found that the pressure drop was independent of mass flux in the two-phase region. They [9] related this observation to the balance between the frictional pressure drop and accelerational pressure drop with the moderate inlet subcooling considered in their tests, which is in contrast to the very modest subcooling used in the current work.

In Figure 10, the pressure drop is presented for different channel sizes at a fixed mass flux as a function of wall heat flux. In both the single-phase and two-phase regions, the pressure drop increases with decreasing microchannel width at a given wall flux. In the two-phase region, the slope of the line also increases as the channel width decreases, resulting in much larger pressure drops for smaller channels at higher heat fluxes.

Figure 11 shows the pumping power required to manage a given heat sink base heat flux with different microchannel sizes. In the single-phase region the pumping power required is almost constant, independent of the heat flux, while in the two phase region, the pumping power increases rapidly with heat flux. This figure also shows that for microchannels of width $400 \mu \mathrm{m}$ and larger, the pumping power is not a strong function of microchannel width. For widths below $400 \mu \mathrm{m}$, however, the pumping power increases for a given base heat flux. Therefore, for a given pumping power, more heat can be removed from the heat source with larger microchannels, although, as discussed in the previous section, using the larger microchannels results in higher wall temperatures. The maximum heat that can be removed from the chip is higher for smaller channels because of greater surface enhancement. It can be concluded that the $400 \mu \mathrm{m}$ wide microchannel heat sink requires lower pumping power than for widths of $100 \mu \mathrm{m}$ and $250 \mu \mathrm{m}$, while at the same time providing a larger heat removal capability and lower wall temperature for a given base heat flux compared to channels that are of $700 \mu \mathrm{m}$ and larger widths.

\section{Comparison to Existing Correlations}

The experimental results obtained in the present work are compared to predictions from a range of correlations from the literature. Of the many predictive correlations for boiling heat transfer proposed in 
the literature, those by Cooper [27] and Gorenflo [28] are widely used for predicting nucleate pool boiling heat transfer coefficients. Flow boiling features simultaneous contributions from nucleate boiling and forced convection. There have been two main approaches to model flow boiling: a superposition approach and an extrapolation approach [12]. Chen [29] proposed the first correlation of the superposition type, in which the nucleate boiling and forced convection components were linearly summed with the introduction of a suppression factor for the nucleate boiling term and an enhancement factor for the forced convection term. Shah [30] proposed an extrapolation-type correlation which used a boiling number and a convective number. After these two early studies, many modifications have been proposed to both approaches to obtain better agreement with different sets of experimental data. Until the last decade, most experiments were performed in large channels with diameters of the order of a few millimeters and larger [31,32]. Studies adopting the superposition-type correlations typically employed turbulent flow models for forced convection [31]. In the last decade, experiments have focused on miniand microchannels and the forced convection component in flow boiling correlations has been targeted at laminar or developing flows $[12,33,34,35]$ to better match the flow conditions in mini- and microchannels. The pool boiling and flow boiling correlations used in the comparisons in the present study are listed in Table 2.

These comparisons are illustrated in Figure 12 for two different channel dimensions and two mass fluxes. Among all the correlations considered, including those for pool boiling and flow boiling, Cooper's nucleate pool boiling correlation [27] best predicts the experimental results from the present work. The mean absolute percentage error (MAPE) in the predictions from Cooper's correlation for all seven test pieces and all the mass fluxes are included in the last column of Table 1. Except for the 100 $\mu \mathrm{m}$ and $250 \mu \mathrm{m}$ wide microchannels for a mass flux of $250 \mathrm{~kg} / \mathrm{m}^{2} \mathrm{~s}$, for which the MAPE is $25.9 \%$ and $19.5 \%$, respectively, the MAPE for all other cases is less than $12.2 \%$. The larger errors for the $100 \mu \mathrm{m}$ and $250 \mu \mathrm{m}$ wide microchannels with lowest mass flux indicate that the boiling regime is not fully governed by nucleate boiling in these two cases and forced convection contributes to the boiling heat transfer. This conclusion is consistent with the earlier discussion of the boiling curves.

Correlations proposed by Peters et al. [35] and Warrier et al. [33] generally overpredict the experimental results for small microchannels or low mass fluxes and underpredict those for the large channels with high mass fluxes. The other correlations $[28,29,30,31,32,34,12]$ highly overpredict the experimental results for all tested microchannels and mass fluxes.

As shown in Figure 12 and discussed earlier, except for the very high heat fluxes, $\mathrm{h}$ increases with increasing heat flux. Some of the examined correlations $[27,28,32]$ show this dependency of $h$ on heat flux correctly, while some others $[29,30,31,34,35]$ only show this trend for large mass fluxes. 
It may be concluded that for the range of parameters considered in the present study, heat transfer coefficient predictions from Cooper's correlation are very satisfactory for flow boiling in microchannels of width larger than $100 \mu \mathrm{m}$ and mass fluxes larger than $250 \mathrm{~kg} / \mathrm{m}^{2} \mathrm{~s}$.

\section{CONCLUSIONS}

The effect of channel dimensions and mass flux on flow boiling heat transfer of FC-77 through microchannel heat sinks has been experimentally investigated.

For a fixed channel size, boiling curves and heat transfer coefficients are independent of mass flux in the nucleate boiling region. As the heat flux is increased further and convective heat transfer becomes dominant, the boiling curves diverge and more heat is dissipated as the mass flux increases for the same wall temperatures. The maximum heat transfer coefficient, as well as the wall heat flux at which this maximum occurs, increase with increasing mass flux.

Pressure drop decreases slightly with heat flux in the single-phase region and increases rapidly with heat flux in the two-phase region. For a fixed wall heat flux, pressure drop increases with increasing mass flux and decreasing channel width.

For a fixed wall heat flux, the heat transfer coefficient is independent of channel width for microchannels of width $400 \mu \mathrm{m}$ and larger, and has a weak dependence on channel width for smaller microchannels. However, for a given amount of heat dissipation from the heat source, the heat transfer coefficient increases with increasing channel width. For microchannels of width $400 \mu \mathrm{m}$ and larger, boiling curves are also independent of channel width.

Although for a fixed pumping power the base heat flux increases with increasing width of the microchannels, the maximum heat that can be removed from the chip increases with decreasing channel width. Also, for a given amount of heat dissipation from the chip, the wall temperature is lower for the smaller channels.

The correlation of Cooper [27] for nucleate pool boiling predicts the experimental heat transfer coefficients very well, with an average mean absolute percentage error of $9 \%$. This error is larger for smaller microchannels and lower mass fluxes. It may be concluded that flow boiling is mainly governed by nucleate boiling for all the cases studied except for the $100 \mu \mathrm{m}$ and $250 \mu \mathrm{m}$ wide microchannels for a mass flux of $250 \mathrm{~kg} / \mathrm{m}^{2} \mathrm{~s}$, and that convective boiling becomes important as the channel width and mass flux decrease.

In ongoing work, the experimental heat transfer measurements from this study are being correlated with experimentally visualized two-phase flow regimes existing under the conditions of the experiment so that regime-based heat transfer and pressure drop models may be developed. 


\section{Acknowledgements}

Financial support from members of the Cooling Technologies Research Center, an NSF Industry/University Cooperative Research Center at Purdue University, is gratefully acknowledged. The authors thank Bruce Myers and Darrel Peugh of Delphi Electronics and Safety, Kokomo, Indiana, for providing the silicon test pieces.

\section{REFERENCES}

[1] Garimella, S. V., Singhal, V., and Liu, D., 2006, “On-Chip Thermal Management with Microchannel Heat Sinks and Integrated Micropumps," Proceedings of the IEEE, 94 (8), pp. 1534-1548.

[2] Garimella, S. V. and Sobhan, C. B., 2003, “Transport in Microchannels-a Critical Review,” Annual Review of Heat Transfer, 13, pp. 1-50.

[3] Sobhan, C. B. and Garimella, S. V., 2001, "A Comparative Analysis of Studies on Heat Transfer and Fluid Flow in Microchannels," Microscale Thermophysical Engineering, 5, pp. 293-311.

[4] Peng, X. F. and Wang, B. X., 1993, "Forced Convection and Flow Boiling Heat Transfer for Liquid Flowing Through Microchannels," International Journal of Heat and Mass Transfer, 36 (14), pp. 34213427.

[5] Kew, P. A. and Cornwell, K., 1997, "Correlations for the Prediction of Boiling Heat Transfer in SmallDiameter Channels,” Applied Thermal Engineering, 17, pp. 705-715.

[6] Qu, W. and Mudawar, I., 2004, “Transport Phenomena in Two-Phase Micro-Channel Heat Sinks,” Journal of Electronic Packaging, 126, pp. 213-224.

[7] Jiang, L., Wong, M., and Zohar, Y., 2001, "Forced Convection Boiling in a Microchannel Heat Sink," Journal of Microelectromechanical Systems, 10, pp. 80-87.

[8] Honda, H. and Wei, J. J., 2004, "Enhanced Boiling Heat Transfer from Electronic Components by Use of Surface Microstructures,” Experimental Thermal and Fluid Science, 28, pp. 159-169.

[9] Chen, T. and Garimella, S. V., 2006, "Measurements and High-Speed Visualization of Flow Boiling of a Dielectric Fluid in a Silicon Microchannel Heat Sink," International Journal of Multiphase Flow, 32 (8), pp. 957-971.

[10] Zhang, H. Y., Pinjala, D., and Wong T. N., 2005, "Experimental Characterization of Flow Boiling Heat Dissipation in a Microchannel Heat Sink with Different Orientations," Proceeding of $7^{\text {th }}$ Electronics Packaging Technology Conference, EPTC, 2, pp. 670-676.

[11] Warrier, G. R., Dhir, V. K., and Momoda, L. A., 2002, "Heat Transfer and Pressure Drop in Narrow Rectangular Channels," Experimental Thermal and Fluid Science, 26, pp. 53-64. 
[12] Liu, D. and Garimella, S. V., 2007, "Flow Boiling Heat Transfer in Microchannels," Journal of Heat Transfer, 129 (10), pp. 1321-1332.

[13] Chen, T. and Garimella, S. V., 2006, "Flow Boiling Heat Transfer to a Dielectric Coolant in a Microchannel Heat Sink," IEEE Transactions on Components and Packaging Technologies, 30 (1), pp. 24-31.

[14] Pate, D. P., Jones, R. J., and Bhavnani, S. H., 2006, “Cavity-Induced Two-Phase Heat Transfer in Silicon Microchannels," Proceedings of the Intersociety Conference on Thermal and Thermomechanical Phenomena and Emerging Technologies in Electronic Systems, pp. 71-78.

[15] Lin, S., Kew, P. A., and Cornwell, K., 2001, "Flow Boiling of Refrigerant R141b in Small Tubes," Chemical Engineering Research and Design, 79 (4), pp. 417-424.

[16] Zhang, L., Wang, E. N., Goodson, K. E., and Kenny, T. W., 2005, "Phase Change Phenomena in Silicon Microchannels,” International Journal of Heat and Mass Transfer, 48, pp. 1572-1582.

[17] Bergles, A. E., Lienhard, J. H., Kendall, G. E., and Griffith, P., 2003, "Boiling and Evaporation in Small Diameter Channels," Heat Transfer Engineering, 24 (1), pp. 18-40.

[18] Saitoh, S., Daiguji, H., and Hihara, E., 2005, "Effect of Tube Diameter on Boiling Heat Transfer of R-134a in Horizontal Small-Diameter Tubes," International Journal of Heat and Mass Transfer, 48 (2324), pp. 4973-4984.

[19] Lee, M., Cheung, L. S. L., Lee, Y., and Zohar, Y., 2005, "Height Effect on Nucleation-Site Activity and Size-Dependent Bubble Dynamics in Microchannel Convective Boiling,” Journal of Micromechanics and Microengineering, 15, pp. 2121-2129.

[20] Lee, M., Wong, Y. Y., Wong, M., and Zohar, Y., 2003, "Size and Shape Effects on Two-Phase Flow Patterns in Microchannel Forced Convection Boiling," Journal of Micromechanics and Microengineering, 13, pp. 155-164.

[21] Dupont, V. and Thome, R., 2005, "Evaporation in Microchannels: Influence of the Channel Diameter on Heat Transfer," Microfluidics and Nanofluidics, 1 (2), pp. 119-127.

[22] Chen, T. and Garimella, S. V., 2006, "Effect of Dissolved Air on Subcooled Flow Boiling of a Dielectric Coolant in a Microchannel Heat Sink,” Journal of Electronic Packaging, 128 (4), pp. 398-404. [23] Lee, P-S. and Garimella, S. V., 2008, "Saturated Flow Boiling Heat Transfer and Pressure Drop in Silicon Microchannel Arrays," International Journal of Heat and Mass Transfer, 51 (3-4), pp. 789-806. [24] Incropera, F. P., DeWitt, D. P., Bergman, T. L., Lavine, A. S., 2007, Fundamentals of Heat and Mass Transfer, $6^{\text {th }}$ Ed., John Wiley \& Sons. 
[25] Taylor, J. R., 1997, An Introduction to Error Analysis, $2^{\text {nd }}$ Ed., University Science Books.

[26] Carey, V. P., 1992, Liquid-Vapor Phase Change Phenomena, Hemisphere Publishing Corp., Washington, pp. 483-490.

[27] Cooper, M. G., 1984, "Heat Flow Rates in Saturated Nucleate Pool Boiling - a Wide-Ranging

Examination Using Reduced Properties," Advances in Heat Transfer, 16, pp. 157-239.

[28] Gorenflo, D., 1993, in VDI Heat Atlas, Chapter Ha.

[29] Chen, J. C., 1966, “Correlation for Boiling Heat Transfer to Saturated Fluids in Convective Flow," Industrial and Engineering Chemistry - Process Design and Development, 5 (3), pp. 322-329.

[30] Shah, M. M., 1977, “General Correlation for Heat Transfer During Subcooled Boiling in Pipes and Annuli," ASHRAE Transactions, 83 (Pt 1), pp. 202-217.

[31] Gungor, K. E. and Winterton, R. H. S., 1986, "General Correlation for Flow Boiling in Tubes and Annuli," International Journal of Heat and Mass Transfer, 29 (3), pp. 351-358.

[32] Tran, T. N., Wambsganss, M. W., and France, D. M., 1996, “Small Circular- and RectangularChannel Boiling with Two Refrigerants," International Journal of Multiphase Flow, 22 (3), pp. 485-498. [33] Warrier G. R., Dhir, V. K., and Momoda, L. A., 2002, "Heat Transfer and Pressure Drop in Narrow Rectangular Channels," Experimental Thermal and Fluid Science, 26 (1), pp. 53-64.

[34] Zhang, W., Hibiki, T., and Mishima, K., 2004, “Correlation for Flow Boiling Heat Transfer in MiniChannels;" International Journal of Heat and Mass Transfer, 47 (26), pp. 5749-5763.

[35] Peters, J. V. S. and Kandlikar, S. G., 2007, "Further Evaluation of a Flow Boiling Correlation for Microchannels and Minichannels," Proceedings of the Fifth International Conference on Nanochannels, Microchannels and Minichannels, ICNMM2007, June 18-20, 2007, Puebla, Mexico. 


\section{LIST OF TABLES}

Table 1. Microchannel dimensions and mass fluxes used in the current study (the four mass fluxes are referred to in the rest of the paper by the nominal values of $250,700,1150$ and $1600 \mathrm{~kg} / \mathrm{m} 2 \mathrm{~s}$; similarly, channel dimensions are referred to by their nominal values for convenience).

Table 2. Summary of boiling heat transfer correlations.

\section{LIST OF FIGURES}

Figure 1. Schematic illustration of the flow loop.

Figure 2. (a) Microchannel test section, and (b) integrated heaters and temperature sensors in the microchannel test piece.

Figure 3. Schematic illustration of the microchannel heat sink (not drawn to scale).

Figure 4. Effect of mass flux on boiling curves for microchannels of width (a) $400 \mu \mathrm{m}$, and (b) $2200 \mu \mathrm{m}$.

Figure 5. (a) Effect of microchannel width on boiling curves, and (b) variation of base heat flux with wall excess temperature for different microchannel widths.

Figure 6. Effect of mass flux on local heat transfer coefficient.

Figure 7. Effect of microchannel width on local heat transfer coefficient as a function of: (a) wall heat flux, and (b) base heat flux.

Figure 8. Variation of exit vapor quality with wall heat flux for different microchannel widths.

Figure 9. Effect of mass flux on pressure drop.

Figure 10. Effect of microchannel width on pressure drop.

Figure 11. Effect of microchannel size on pumping power.

Figure 12. Comparison of correlations in literature for heat transfer coefficients. 
Table 1. Microchannel dimensions and mass fluxes used in the current study (the four mass fluxes are referred to in the rest of the paper by the nominal values of $250,700,1150$ and $1600 \mathrm{~kg} / \mathrm{m}^{2} \mathrm{~s}$; similarly, channel dimensions are referred to by their nominal values for convenience).

\begin{tabular}{|c|c|c|c|c|c|c|}
\hline $\begin{array}{l}\text { w }(\mu \mathrm{m}) \\
\text { (nominal } \\
\text { values) } \\
\end{array}$ & $\begin{array}{c}\mathrm{w}_{\mathrm{f}}(\mu \mathrm{m}) \\
\text { (nominal } \\
\text { values) } \\
\end{array}$ & $\begin{array}{c}\mathrm{d}(\mu \mathrm{m}) \\
\text { (nominal } \\
\text { values) } \\
\end{array}$ & $\mathrm{N}$ & $\mathrm{G}\left(\mathrm{kg} / \mathrm{m}^{2} \mathrm{~s}\right)$ & Maximum $x_{e}(\%)$ & $\begin{array}{c}\text { Deviation }{ }^{\dagger} \text { between } \\
h_{\text {exp }} \text { and } h_{\text {pred }}[27] \\
(\%)\end{array}$ \\
\hline $\begin{array}{l}101.5 \\
(100)\end{array}$ & $\begin{array}{l}101.9 \\
(100)\end{array}$ & $\begin{array}{l}369.4 \\
(400)\end{array}$ & 60 & $267,700,1150,1600$ & $\begin{array}{c}\text { superheated, } 74,48 \\
32\end{array}$ & $25.9,12.1,8.1,4.7$ \\
\hline $\begin{array}{l}239.1 \\
(250)\end{array}$ & $\begin{array}{l}110.8 \\
(100)\end{array}$ & $\begin{array}{l}371.4 \\
(400)\end{array}$ & 35 & $248,700,1150,1595$ & $\begin{array}{c}\text { superheated, } 49,31 \\
23\end{array}$ & $19.5,12.2,10.7,9$ \\
\hline $\begin{array}{l}394.6 \\
(400)\end{array}$ & $\begin{array}{l}105.4 \\
(100)\end{array}$ & $\begin{array}{l}364.9 \\
(400)\end{array}$ & 24 & $250,700,1150,1600$ & $77,35,21,15$ & $9.4,7,9.3,10.8$ \\
\hline $\begin{array}{l}686.3 \\
(700)\end{array}$ & $\begin{array}{l}154.1 \\
(150)\end{array}$ & $\begin{array}{l}375.6 \\
(400)\end{array}$ & 14 & $240,680,1120,1560$ & $64,32,19,11$ & $10.3,6.1,5.1,3$ \\
\hline $\begin{array}{l}978.4 \\
(1000)\end{array}$ & $\begin{array}{l}222.3 \\
(200)\end{array}$ & $\begin{array}{l}373.7 \\
(400)\end{array}$ & 10 & $246,700,1152,1600$ & $52,23,15,8$ & $10.7,6.9,3.8,4.1$ \\
\hline $\begin{array}{l}2202.8 \\
(2200)\end{array}$ & $\begin{array}{l}280 \\
(300)\end{array}$ & $\begin{array}{l}370.1 \\
(400)\end{array}$ & 5 & $249,702,1151,1601$ & $30,15,9,4$ & $6.8,5.9,6.7,7.7$ \\
\hline $\begin{array}{l}5850.5 \\
(5850)\end{array}$ & $\begin{array}{c}300 \\
(300)\end{array}$ & $\begin{array}{l}376.2 \\
(400)\end{array}$ & 2 & $250,701,1149$ & $29,15,9$ & $10,7.2,6.1$ \\
\hline
\end{tabular}
$\dagger$ Deviation of heat transfer coefficient obtained from the experiments and predicted by Cooper's correlation [27] is presented in
terms of Mean Absolute Percentage Error. 
Table 2. Summary of boiling heat transfer correlations.

\begin{tabular}{|c|c|c|c|c|c|}
\hline Reference & Fluid & Geometry & $\begin{array}{l}\text { Parameters rangel } \\
\text { Flow regime }\end{array}$ & Correlation for $h$ & \\
\hline $\begin{array}{l}\text { Cooper [27] } \\
1984\end{array}$ & $\begin{array}{l}\text { Water, } \\
\text { refrigerant, } \\
\text { organic } \\
\text { fluids } \\
\end{array}$ & Pool boiling & $\begin{array}{c}0.001<p_{r}<0.9 \\
2<\mathrm{M}<200 \\
\text { Nucleate pool boiling }\end{array}$ & $h_{n b}=55 p_{r}^{0.12-0.4343 \ln R_{p}}\left(-0.4343 \ln p_{r}\right)^{-0.55} M^{-0.5} q^{\prime 0.67}$ & (8) \\
\hline $\begin{array}{c}\text { Gorenflo } \\
\text { [28] } \\
1993\end{array}$ & $\begin{array}{l}\text { Large } \\
\text { selection of } \\
\text { fluids }\end{array}$ & Pool boiling & $\begin{array}{c}0.0005<p_{r}<0.95 \\
\text { Nucleate pool boiling }\end{array}$ & $\begin{array}{l}h_{n b}=h_{0} F_{P F}\left(q^{\prime \prime} / q_{0}^{\prime \prime}\right)^{n}\left(R_{p} / R_{p 0}\right)^{0.133}, h_{0}=4200 \mathrm{~W} / \mathrm{m}^{2} \mathrm{~K} \text { for RC318 } \\
F_{P F}=1.2 p_{r}^{0.27}+2.5 p_{r}+p_{r} /\left(1-p_{r}\right) \\
n=0.9-0.3 p_{r}^{0.3}\end{array}$ & $\begin{array}{l}(9) \\
(10) \\
(11)\end{array}$ \\
\hline $\begin{array}{l}\text { Chen [29] } \\
1966\end{array}$ & $\begin{array}{l}\text { Water \& } \\
\text { organic } \\
\text { fluids }\end{array}$ & $\begin{array}{l}\text { Vertical tubes } \\
\quad \& \text { annuli }\end{array}$ & $\begin{array}{c}0.55<P<34.8 \mathrm{bar} \\
0.06<u_{i}<4.5 \mathrm{~m} / \mathrm{s} \\
1<x<71 \% \\
6.2<q "<2400 \mathrm{~kW} / \mathrm{m}^{2} \\
\text { Saturated flow boiling }\end{array}$ & $\begin{array}{l}h_{t p}=S h_{n b}+F h_{s p} \\
h_{s p}=0.023\left[(1-x) \operatorname{Re}_{f}\right]^{0.8} \operatorname{Pr}_{f}^{0.4}\left(k_{f} / D\right) \\
h_{n b}=0.00122\left(\frac{k_{f}^{0.79} c_{p f}^{0.45} \rho_{f}^{0.49}}{\sigma^{0.5} \mu_{f}^{0.29} h_{f g}^{0.24} \rho_{g}^{0.24}}\right)\left(\Delta T_{s a t}\right)^{0.24}\left(\Delta p_{s a t}\right)^{0.75} \\
F=f\left(X_{t t}\right), S=f(\mathrm{Re})\end{array}$ & $\begin{array}{l}(12) \\
(13) \\
(14) \\
(15)\end{array}$ \\
\hline $\begin{array}{l}\text { Shah [30] } \\
1977\end{array}$ & $\begin{array}{c}\text { Water, } \\
\text { refrigerants } \\
\text { (R11, R12, } \\
\text { R22, R502) }\end{array}$ & $\begin{array}{l}\text { Horizontal \& } \\
\text { vertical tubes } \\
D=6-41 \mathrm{~mm}\end{array}$ & $\begin{array}{l}\quad 0.004<p_{r}<0.8 \\
\text { Saturated flow boiling }\end{array}$ & $\begin{array}{l}h_{t p} / h_{s p}=\max \left(\psi_{n b}, \psi_{c b}\right) \\
h_{s p}=0.023\left[(1-x) \operatorname{Re}^{0.8} \operatorname{Pr}_{f}^{0.4}\left(k_{f} / D\right)\right. \\
\psi_{n b}=f(B o, C o), \psi_{c b}=f(C o)\end{array}$ & $\begin{array}{l}(16) \\
(17) \\
(18)\end{array}$ \\
\hline $\begin{array}{c}\text { Gungor \& } \\
\text { Winterton } \\
{[31]} \\
1986\end{array}$ & $\begin{array}{l}\text { Water, } \\
\text { refrigerants } \\
\text {, ethylene } \\
\text { glycol }\end{array}$ & $\begin{array}{l}\text { Horizontal \& } \\
\text { vertical tubes } \\
\& \text { annuli } \\
D=3-32 \mathrm{~mm}\end{array}$ & $\begin{array}{c}0.08<P_{\text {sat }}<203 \mathrm{bar} \\
12<\mathrm{G}_{i}<61518 \mathrm{~kg} / \mathrm{m}^{2} \mathrm{~s} \\
0<x<173 \% \\
1<q^{\prime \prime}<91534 \mathrm{~kW} / \mathrm{m}^{2} \\
\text { Saturated \& subcooled flow } \\
\text { boiling }\end{array}$ & $\begin{array}{l}h_{t p}=S h_{n b}+F h_{s p} \\
h_{s p}=0.023[(1-x) \mathrm{Re}]^{0.8} \operatorname{Pr}_{f}^{0.4}\left(k_{f} / D\right) \\
h_{n b}=55 p_{r}^{0.12}\left(-0.4343 \ln p_{r}\right)^{-0.55} M^{-0.5} q^{\prime \prime 0.67} \\
F=f\left(B o, X_{t t}\right), S=f(\mathrm{Re})\end{array}$ & $\begin{array}{l}(19) \\
(20) \\
(21) \\
(22)\end{array}$ \\
\hline $\begin{array}{c}\text { Tran et al. } \\
{[32]} \\
1996\end{array}$ & $\begin{array}{c}\text { Refrigerant } \\
\text { s (R12, } \\
\text { R113) }\end{array}$ & $\begin{array}{l}\text { Horizontal } \\
\text { circular \& } \\
\text { rectangular } \\
\text { channels of } \\
\mathrm{D}_{\mathrm{h}} \sim 2.4 \mathrm{~mm}\end{array}$ & $\begin{array}{c}P_{\text {sat }}=0.8 \mathrm{Mpa} \\
44<\mathrm{G}_{i}<832 \mathrm{~kg} / \mathrm{m}^{2} \mathrm{~s} \\
x<94 \% \\
3.6<q^{\prime \prime}<129 \mathrm{~kW} / \mathrm{m}^{2} \\
\text { Nucleation dominant region } \\
\text { in small channels }\end{array}$ & $h_{t p}=8.4 \times 10^{5}\left(B o^{2} W e_{f}\right)^{0.3}\left(\rho_{f} / \rho_{g}\right)^{-0.4}$ & $(23)$ \\
\hline
\end{tabular}




\begin{tabular}{|c|c|c|c|c|c|}
\hline Reference & Fluid & Geometry & $\begin{array}{l}\text { Parameters rangel } \\
\text { Flow regime }\end{array}$ & Correlation for $h$ & \\
\hline $\begin{array}{l}\text { Warrier et } \\
\text { al. [33] } \\
2002\end{array}$ & $\mathrm{FC} 84$ & $\begin{array}{l}\text { Horizontal } \\
\text { rectangular } \\
\text { parallel } \\
\text { channels of } \\
\mathrm{D}_{\mathrm{h}}=0.75 \mathrm{~mm}\end{array}$ & $\begin{array}{c}0.00027<B O<0.00089 \\
3<x<55 \% \\
\text { Saturated flow boiling }\end{array}$ & $h_{t p} / h_{s p, f d}=1+6 B o^{1 / 16}-5.3(1-855 B o) x^{0.65}$ & (24) \\
\hline $\begin{array}{l}\text { Zhang et al. } \\
\text { [34] } \\
2004\end{array}$ & $\begin{array}{l}\text { Water, } \\
\text { refrigerants } \\
\text { (R11, R12, } \\
\text { R113) }\end{array}$ & $\begin{array}{c}\text { Horizontal/ } \\
\text { vertical single } \\
\text { circular/rectan } \\
\text { gular } \\
\text { channels } \\
D_{\mathrm{h}}=0.78-6 \\
\mathrm{~mm}\end{array}$ & $\begin{array}{c}0.101<P<1.21 \mathrm{MPa} \\
23.4<\mathrm{G}_{i}<2939 \mathrm{~kg} / \mathrm{m}^{2} \mathrm{~s} \\
2.95<q^{\prime \prime}<2511 \mathrm{~kW} / \mathrm{m}^{2} \\
\text { Saturated flow boiling in } \\
\text { mini channels }\end{array}$ & $\begin{array}{l}h_{t p}=S h_{n b}+F h_{s p} \\
h_{s p}=\left(k_{f} / D_{h}\right) \max \left(N u_{s p, v}, N u_{s p, t}\right) \text { for } \operatorname{Re}_{f}<2300 \\
h_{s p}=\left(k_{f} / D_{h}\right) N u_{s p, t} \text { for } \operatorname{Re}_{f} \geq 2300 \\
h_{n b}=0.00122\left(\frac{k_{f}^{0.79} c_{p f}^{0.45} \rho_{f}^{0.49}}{\sigma^{0.5} \mu_{f}^{0.29} h_{f g}^{0.24} \rho_{g}^{0.24}}\right)\left(\Delta T_{s a t}\right)^{0.24}\left(\Delta P_{s a t}\right)^{0.75} \\
F=\max \left(0.64 \phi_{f}, 1\right), S=f(\mathrm{Re})\end{array}$ & $\begin{array}{l}(25) \\
(26) \\
(27) \\
(28) \\
(29)\end{array}$ \\
\hline $\begin{array}{l}\text { Peters \& } \\
\text { Kandlikar } \\
\text { [35] } \\
2007\end{array}$ & $\mathrm{R} 123$ & $\begin{array}{c}\text { Circular \& } \\
\text { rectangular } \\
\text { channels of } \\
D_{\mathrm{h}} \sim 0.21 \mathrm{~mm}\end{array}$ & $\begin{array}{c}400<\mathrm{G}_{i}<800 \mathrm{~kg} / \mathrm{m}^{2} \mathrm{~s} \\
25<q^{\prime \prime}<85 \mathrm{~kW} / \mathrm{m}^{2} \\
0<x<70 \% \\
\text { Flow boiling in mini/micro } \\
\text { channels }\end{array}$ & $\begin{array}{l}h_{t p} / h_{s p}=c_{1} \operatorname{Co}^{c_{2}}(1-x)^{0.8}\left(25 F r_{f}\right)^{c_{5}}+c_{3} B o^{c_{4}}(1-x)^{0.8} F_{f l} \\
h_{t p} / h_{s p}=c_{3} B o^{c_{4}}(1-x)^{0.8} F_{f l} \text { for } \operatorname{Re}_{f}<100 \\
h_{s p}=\frac{\left(\operatorname{Re}_{f}-1000\right) \operatorname{Pr}_{f}(f / 2)\left(k_{f} / D\right)}{1+12.7\left(\operatorname{Pr}_{f}^{2 / 3}-1\right)(f / 2)^{0.5}} \text { for } 10^{4}<\operatorname{Re}_{f}<5 \times 10^{6} \\
h_{s p}=\frac{\operatorname{Re}_{f} \operatorname{Pr}_{f}(f / 2)\left(k_{f} / D\right)}{1+12.7\left(\operatorname{Pr}_{f}^{2 / 3}-1\right)(f / 2)^{0.5}} \text { for } 3000<\operatorname{Re}_{f}<10^{4} \\
h_{s p}=\left(k_{f} / D_{h}\right) N u \text { for } \operatorname{Re}_{f}<1600\end{array}$ & $\begin{array}{l}(30) \\
(31)\end{array}$ \\
\hline $\begin{array}{l}\text { Liu \& } \\
\text { Garimella } \\
{[12]}\end{array}$ & Water & $\begin{array}{l}\text { Rectangular } \\
\text { channels } \\
0.3 \times 0.6 \& \\
0.4 \times 1 \mathrm{~mm}\end{array}$ & $\begin{array}{c}221<G_{i}<1283 \mathrm{~kg} / \mathrm{m}^{2} \mathrm{~s} \\
q^{\prime \prime}<1290 \mathrm{~kW} / \mathrm{m}^{2} \\
x<20 \% \\
\text { Saturated flow boiling in } \\
\text { micro channels }\end{array}$ & $\begin{array}{l}h_{t p}=S h_{n b}+F h_{s p} \\
h_{s p}=1.86\left[(1-x) \operatorname{Re}_{f} \operatorname{Pr}_{f} D_{h} / L\right]^{1 / 3}\left(\mu_{f} / \mu_{w}\right)\left(k_{f} / D_{h}\right) \\
h_{n b}=h_{0} F_{P F}\left(q^{\prime \prime} / q_{0}^{\prime \prime}\right)^{n}\left(R_{p} / R_{p 0}\right)^{0.133} \\
F=f\left(\phi_{f}, \mu, c_{p}, k, \operatorname{Pr}\right), S=f(\operatorname{Re}, F)\end{array}$ & $\begin{array}{l}\text { (36) } \\
\text { (37) }\end{array}$ \\
\hline
\end{tabular}




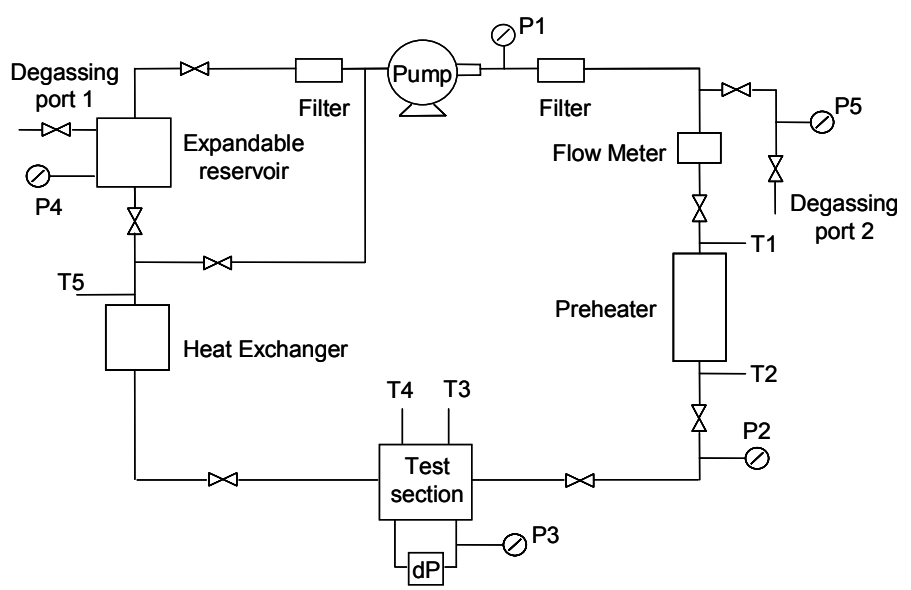

Figure 1. Schematic illustration of the flow loop. 


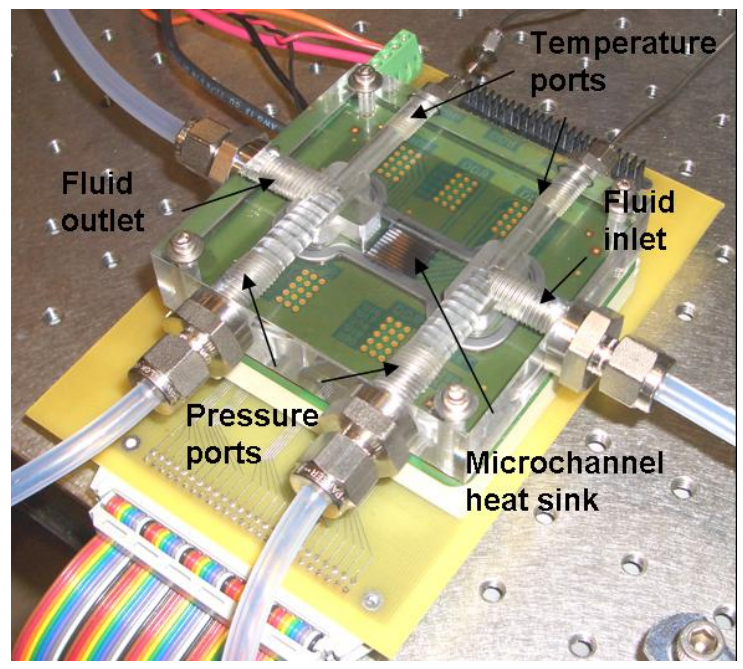

(a)

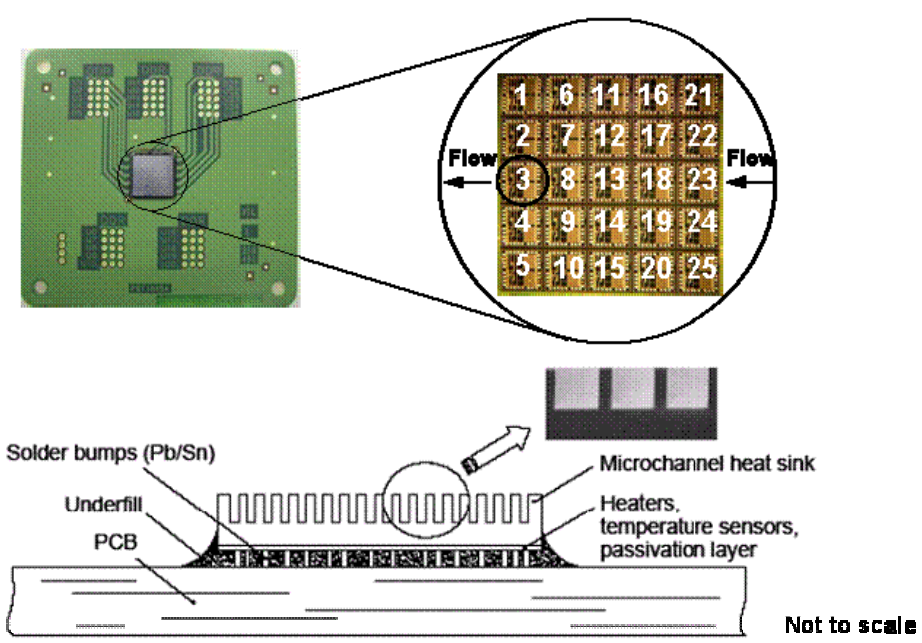

(b)

Figure 2. (a) Microchannel test section, and (b) integrated heaters and temperature sensors in the microchannel test piece. 


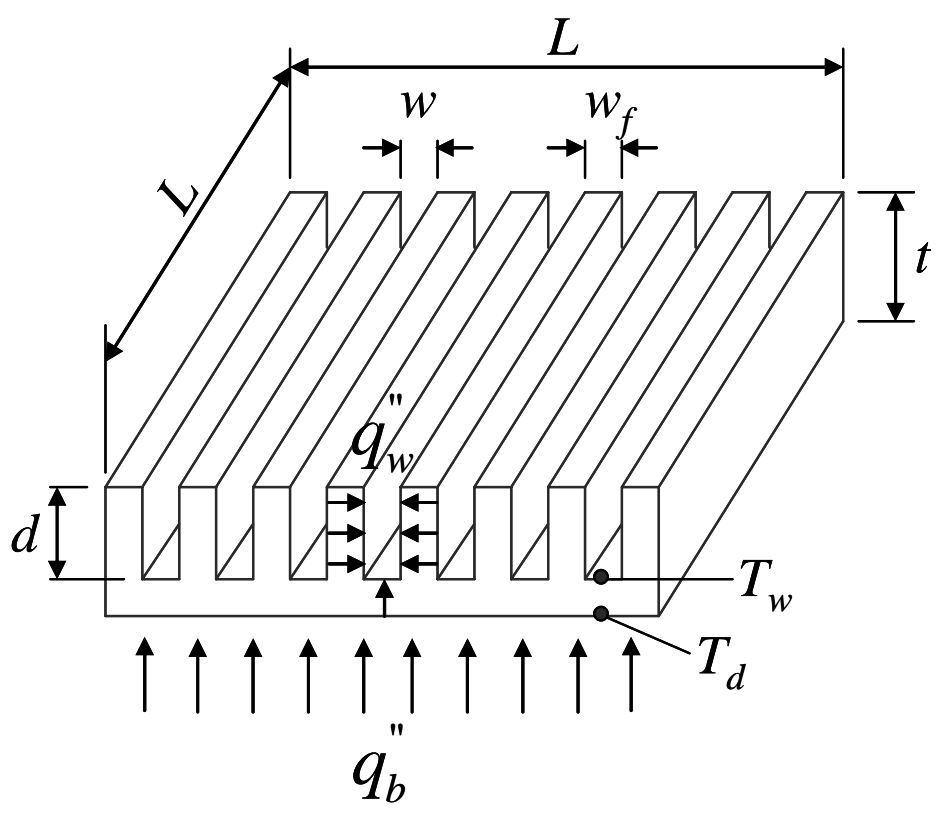

Figure 3. Schematic illustration of the microchannel heat sink (not drawn to scale). 


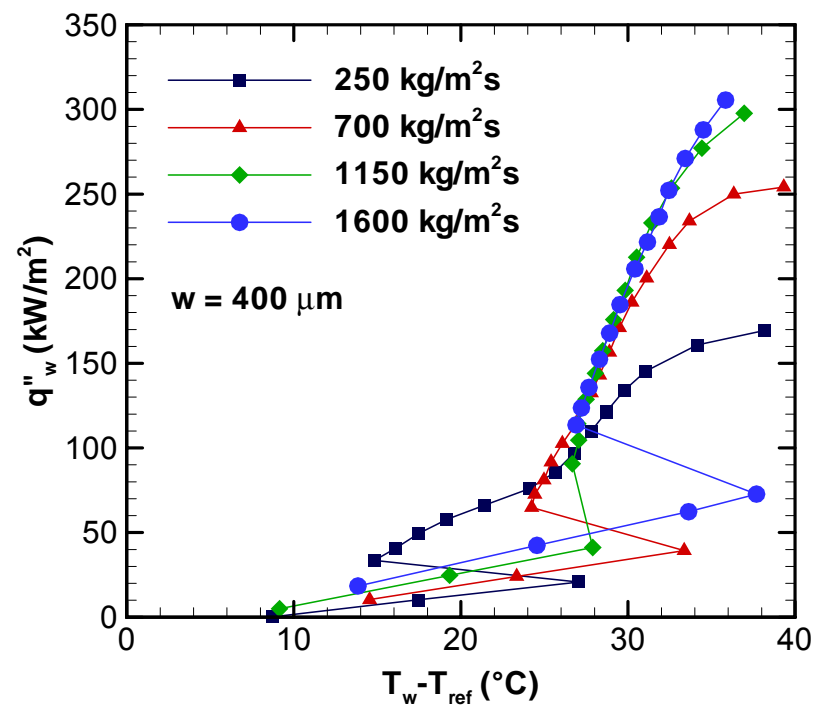

(a)

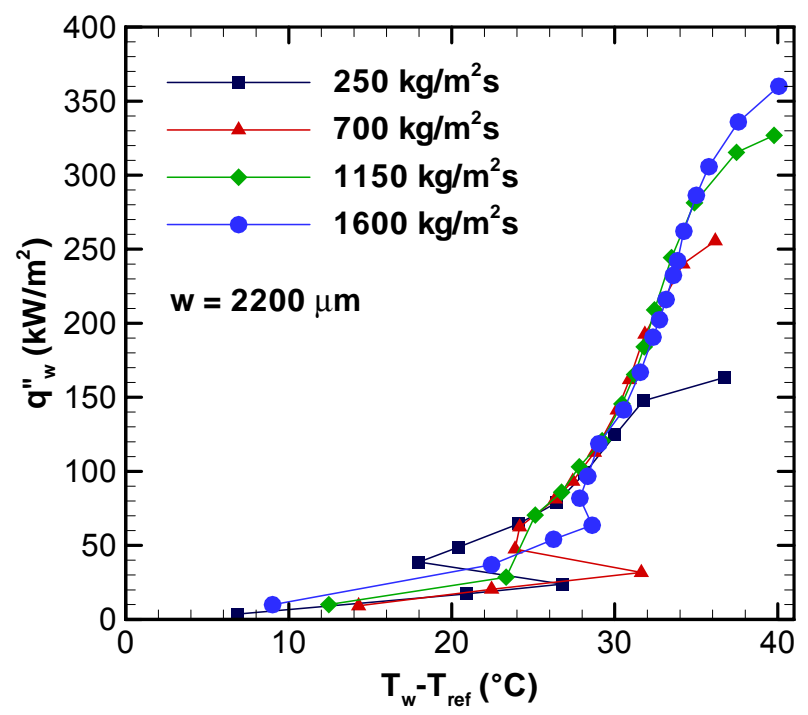

(b)

Figure 4. Effect of mass flux on boiling curves for microchannels of width (a) $400 \mu \mathrm{m}$, and (b) $2200 \mu \mathrm{m}$. 


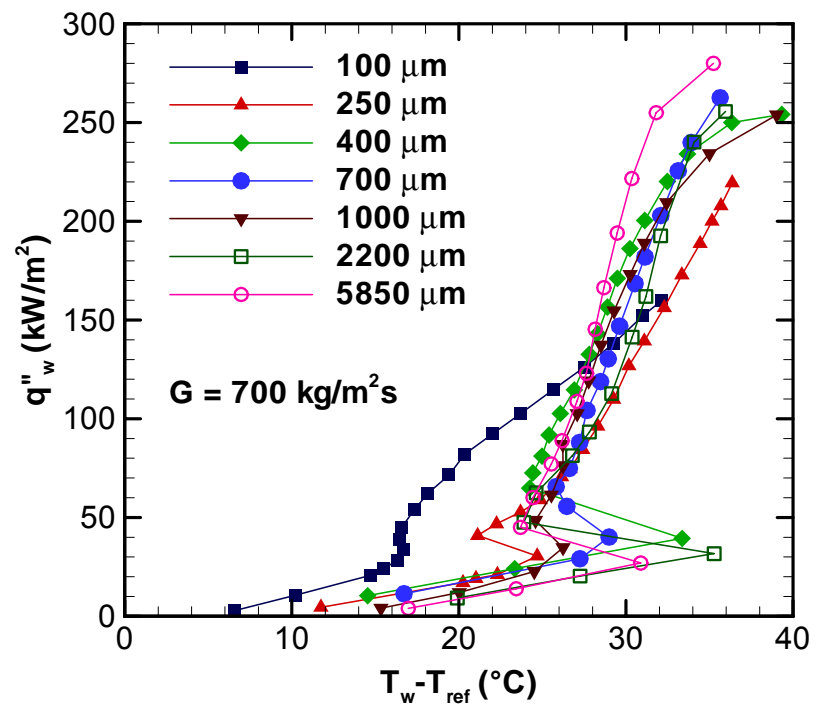

(a)

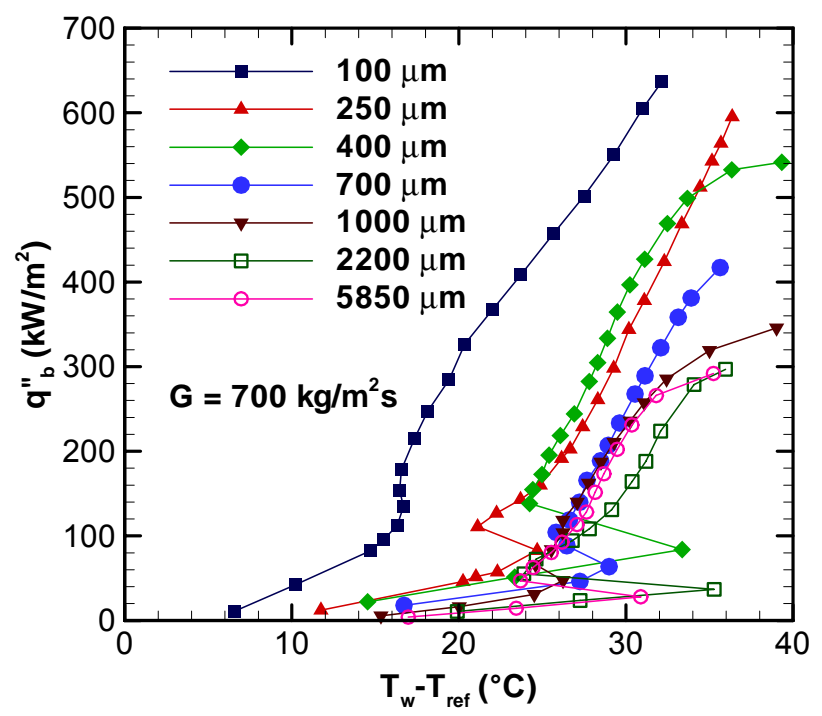

(b)

Figure 5. (a) Effect of microchannel width on boiling curves, and (b) variation of base heat flux with wall excess temperature for different microchannel widths. 


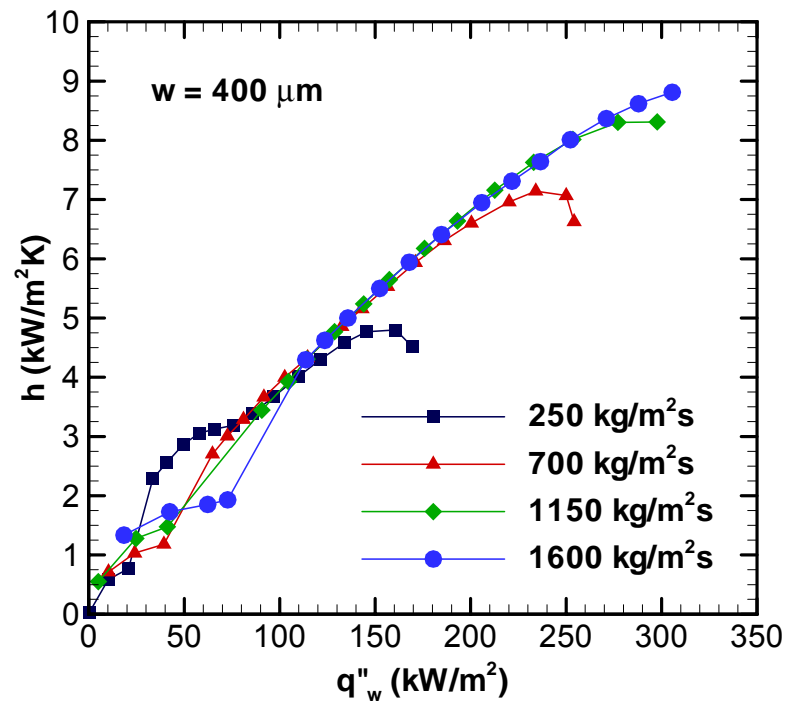

Figure 6. Effect of mass flux on local heat transfer coefficient. 


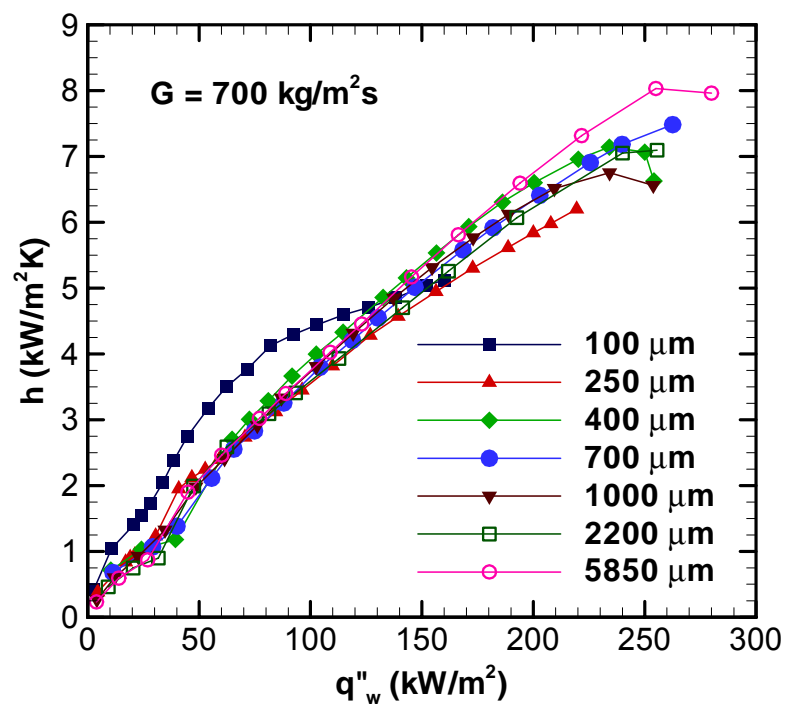

(a)

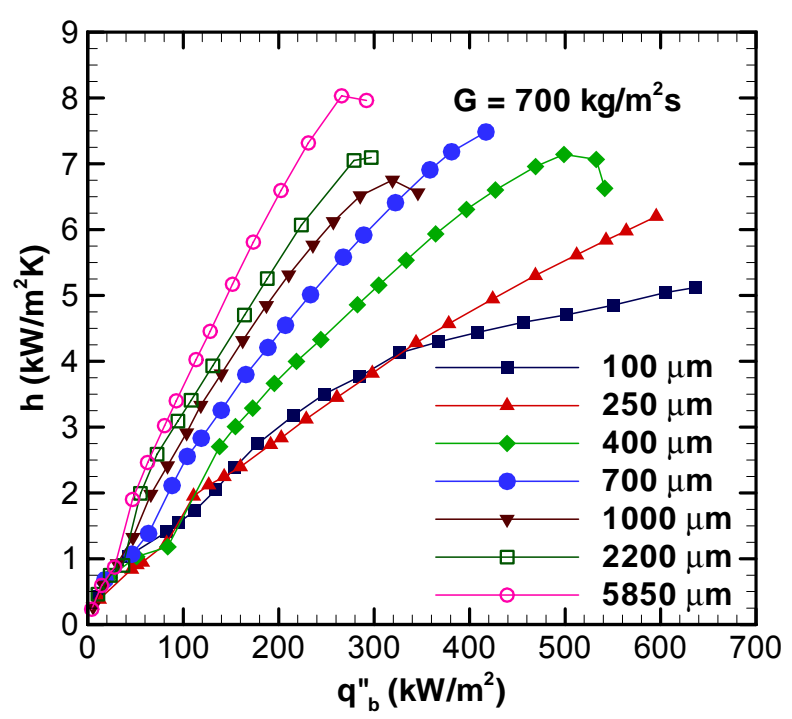

(b)

Figure 7. Effect of microchannel width on local heat transfer coefficient as a function of: (a) wall heat flux, and (b) base heat flux. 


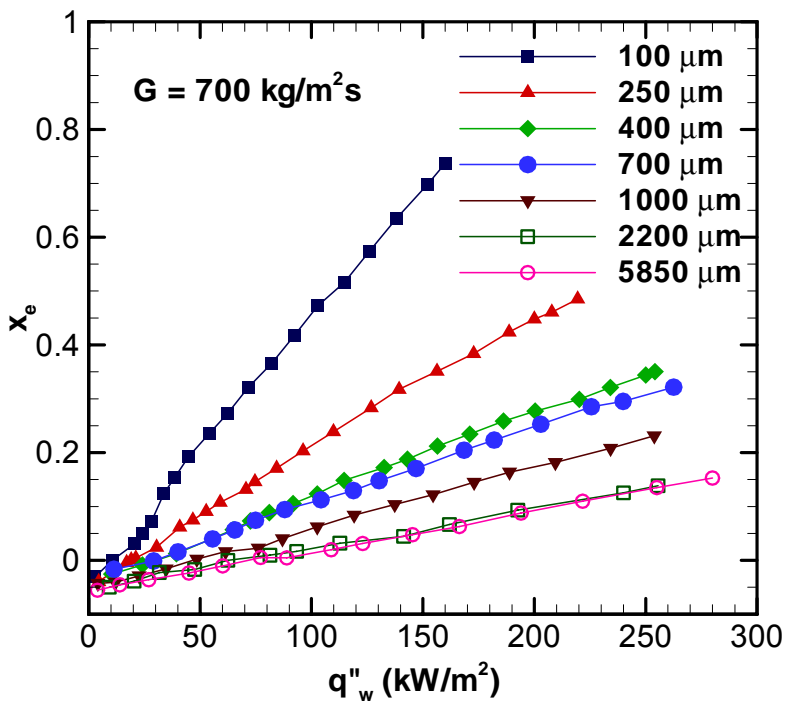

Figure 8. Variation of exit vapor quality with wall heat flux for different microchannel widths. 


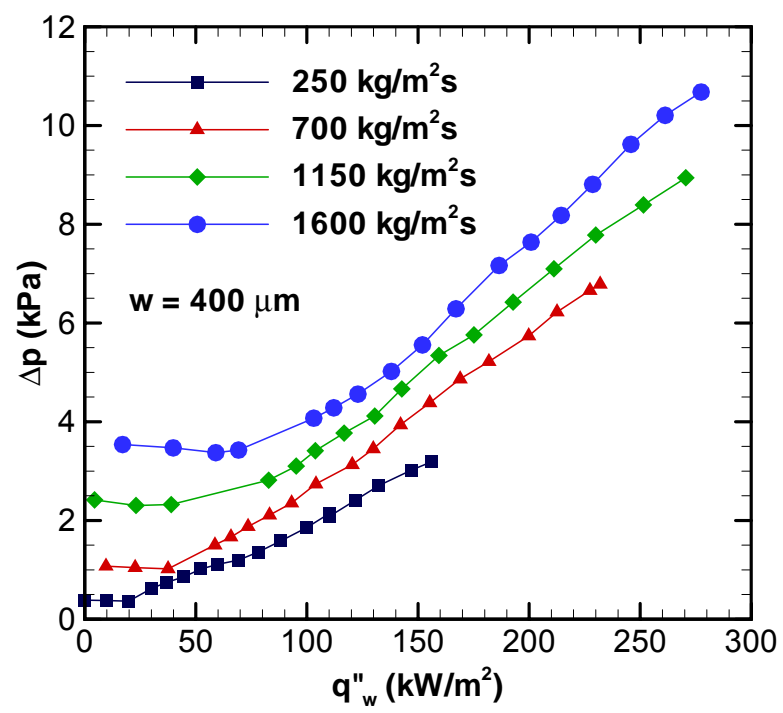

Figure 9. Effect of mass flux on pressure drop. 


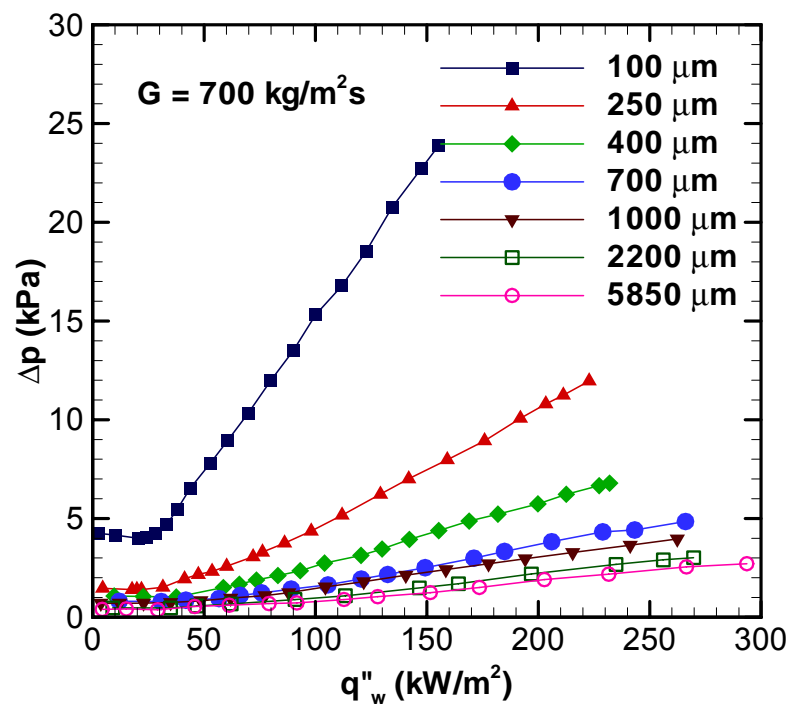

Figure 10. Effect of microchannel width on pressure drop. 


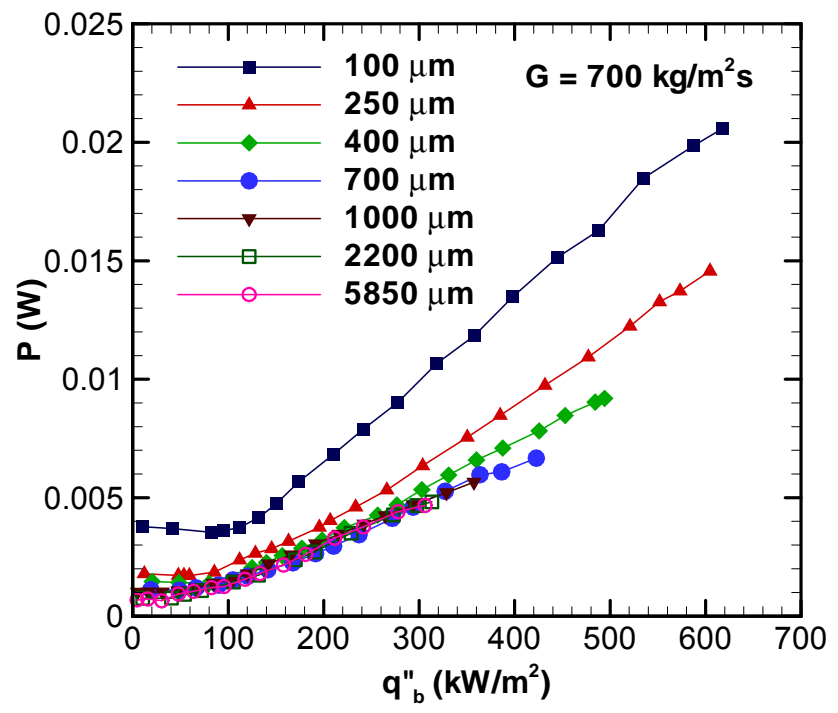

Figure 11. Effect of microchannel size on pumping power. 

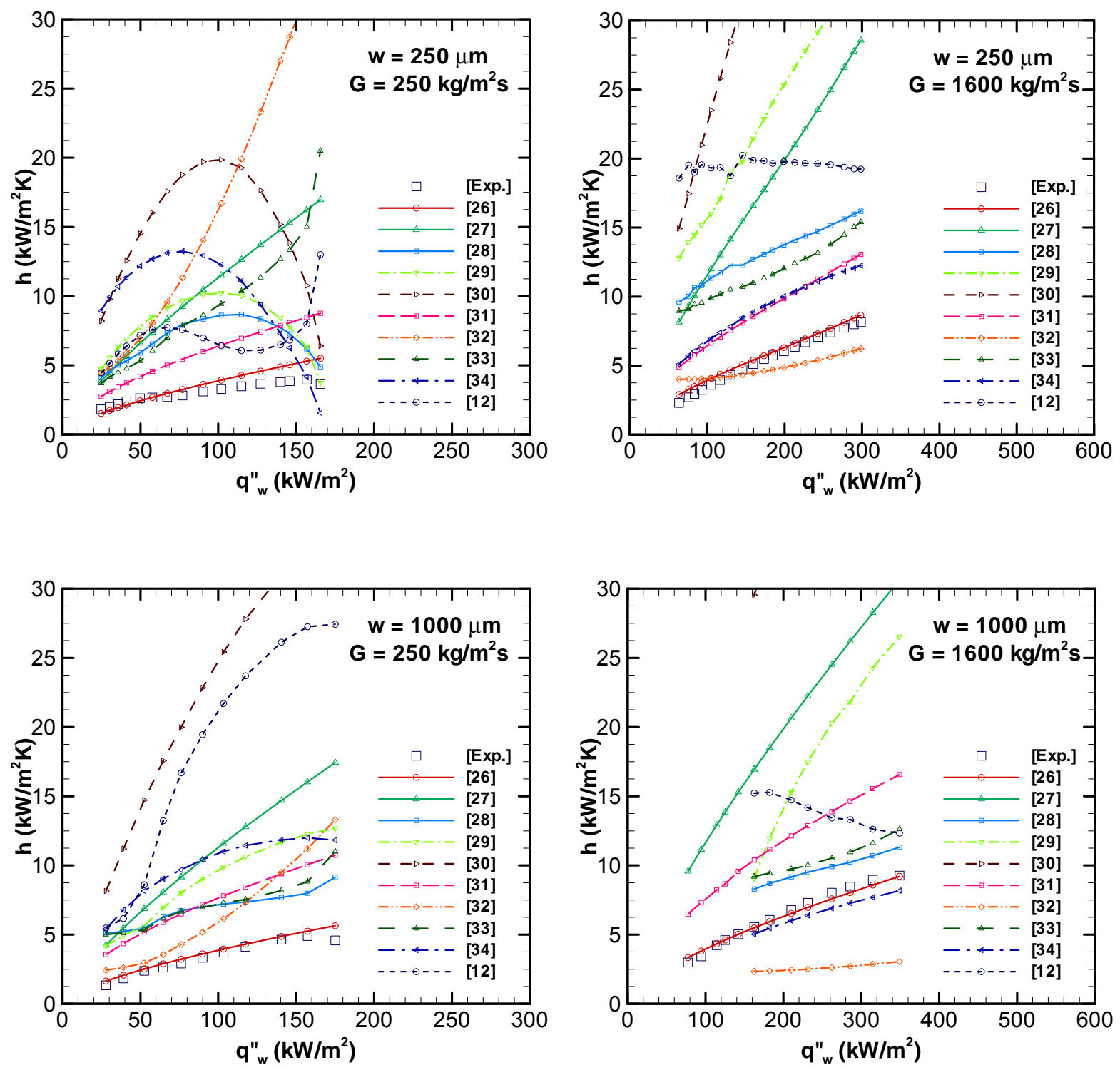

Figure 12. Comparison of correlations in literature for heat transfer coefficients. 